\title{
Spatial Analysis of Phytophthora infestans Genotypes and Late Blight Severity on Tomato and Potato in the Del Fuerte Valley Using Geostatistics and Geographic Information Systems
}

\author{
R. Jaime-Garcia, T. V. Orum, R. Felix-Gastelum, R. Trinidad-Correa, H. D. VanEtten, and M. R. Nelson
}

\begin{abstract}
First, second, fifth, and sixth authors: Department of Plant Pathology, University of Arizona, Tucson 85721; third author: Departamento de Biologia, Universidad de Occidente, Unidad Los Mochis, Los Mochis, Sinaloa C.P. 81223, Mexico; and fourth author: Alimentos Del Fuerte, Los Mochis, Sinaloa 81200, Mexico.

Current address of R. Trinidad-Correa: Agrobo S.A. de C.V. Los Mochis, Sinaloa C.P. 81200, Mexico.

Accepted for publication 2 August 2001.
\end{abstract}

\begin{abstract}
Jaime-Garcia, R., Orum, T. V., Felix-Gastelum, R., Trinidad-Correa, R., VanEtten, H. D., and Nelson, M. R. 2001. Spatial analysis of Phytophthora infestans genotypes and late blight severity on tomato and potato in the Del Fuerte Valley using geostatistics and geographic information systems. Phytopathology 91:1156-1165.

Genetic structure of Phytophthora infestans, the causal agent of potato and tomato late blight, was analyzed spatially in a mixed potato and tomato production area in the Del Fuerte Valley, Sinaloa, Mexico. Isolates of $P$. infestans were characterized by mating type, allozyme analysis at the glucose-6-phosphate isomerase and peptidase loci, restriction fragment length polymorphism with probe RG57, metalaxyl sensitivity, and aggressiveness to tomato and potato. Spatial patterns of $P$. infestans

analysis of the genetic structure of $P$. infestans indicates that geographic substructuring of this pathogen occurs in this area. Maps displaying the probabilities of occurrence of mating types and genotypes of $P$. infestans, and of disease severity at a regional scale, were presented. Some genotypes that exhibited differences in epidemiologically important features such as metalaxyl sensitivity and aggressiveness to tomato and potato had a restricted spread and were localized in isolated areas. Analysis of late blight severity showed recurring patterns, such as the earliest onset of the disease in the area where both potato and tomato were growing, strengthening the hypothesis that infected potato tubers are the main source of primary inoculum. The information that geostatistical analysis provides might help improve management programs for late blight in the Del Fuerte Valley.
\end{abstract} genotypes were analyzed by geographical information systems and geostatistics during the seasons of 1994-95, 1995-96, and 1996-97. Spatial

Population genetic studies of the potato and tomato pathogen Phytophthora infestans (Mont.) de Bary, have intensified since the development of metalaxyl insensitive isolates of the pathogen outside central Mexico. These studies reported changes in the genetic structure of $P$. infestans over large areas such as countries, continents, or even worldwide $(9,10,14)$. New information management technology can describe and display spatial patterns of different genotypes at the scale of an agricultural region. These technologies, geographic information systems (GIS) and geostatistics, have been applied in the study of spatially related data in diverse fields (11) including soil science (38), entomology $(2,23)$, medical entomology (31), and plant pathology $(28-30,33)$. The variety of problems that are addressed by spatial statistics and ways in which GIS can aid in the manipulation of environmental data are illustrated by Myers, Cressie, and VerHoef; Cressie, Jager, and Overton; Englund, Rasmussen-Rhodes, and Myers; and VerHoef, Anselin, and Overton in section VI of the book Environmental Modeling with GIS (12).

Geostatistics offers a means to describe spatial continuity, an essential feature of many natural phenomena, and provides adaptations of classical regression techniques to use continuity for making estimates at unsampled locations $(5,17)$. Furthermore, the modeling of spatial continuity can be used to assess uncertainty associated with estimated values (20). Kriging is a regression

Corresponding author: R. Jaime-Garcia; E-mail address: rjaime@srrc.ars.usda.gov

Publication no. P-2001-0925-01R

(C) 2001 The American Phytopathological Society
Additional keywords: indicator kriging. technique used for the estimation or interpolation of spatially located and spatially correlated data. In addition to obtaining the best linear estimate of the variable at unsampled locations, the variance of error of estimation, which reflects the spatial correlation and the sample location pattern, is also obtained (26).

Plant disease results from the interaction of the host and the pathogen with the environment. Spatial analysis and GIS are natural partners for the analysis and modeling of environmental data (6, 27 ), because data from both an organism and its environment are often spatial in nature. It is appropriate, therefore, to apply spatial analysis tools that are frequently used in environmental studies (11) to plant disease epidemic studies. Geostatistics has been used in the field of plant pathology to analyze plant diseases epidemics often at plot or field scales $(3,16,21,22,35,37)$. Nelson et al. (28) successfully applied this technique to develop a regional risk assessment for the management of plant virus diseases in tomatoes. Stein et al. (35) used geostatistics to determine the source of primary inoculum and the analysis of spatiotemporal development of cabbage downy mildew epidemics. Geostatistics has been used to quantify inoculum patterns at very small scales such as the surface of plant roots (7). Furthermore, it has been applied to determine spatial genetic structures of wild populations (25). A review of the application of GIS and geostatistics in plant disease management has been published (30).

The objective of this study is to analyze the spatial patterns of the genotypes of $P$. infestans and the association of genotypes with disease severity in a mixed tomato and potato production system. This study provides a geostatistical analysis of previously published genotype data (18) and relates genotype probability maps derived by indicator kriging to disease severity maps at a regional 
scale. The tools developed in this study are intended for use in a risk assessment program to improve the integrated management of late blight in a mixed potato and tomato production area.

\section{MATERIALS AND METHODS}

Data collection. The present study was done in the Del Fuerte Valley, Sinaloa, in northwestern Mexico during the seasons of 1994-95, 1995-96, and 1996-97. The study area encompasses a valley of approximately $150 \mathrm{~km}$ long by $60 \mathrm{~km}$ wide. A description of the area of study has been published (18). Fields were surveyed in a opportunistic procedure that was based in part on industry scouting reports of disease incidence in tomato and potato. The number of fields surveyed for each crop is presented in Table 1. Each potato or tomato field surveyed for late blight infection, and each sample location within a field, were geo-referenced with a hand-held global positioning system (GPS) unit (Model 69001; Magellan Systems Corp., San Dimas, CA or Garmin 45, Garmin Corp., Lenexa, KS) in the universal transverse mercator (UTM) coordinate system to be used in geostatistics analysis. The UTM system gives the positions in meters and is preferred over latitudelongitude in decimal degrees because position coordinates in meters facilitate the computation of distances between sample locations in a plane (two dimensions), which is required in a geostatistical analysis. The maximum distance between sample locations was approximately $100 \mathrm{~km}$, and the minimum distance was a few meters within fields.

In fields where late blight was found, infected material was collected for isolation and characterization of $P$. infestans from one to six sites, depending in the size of the field and the incidence of late blight. Each isolate of $P$. infestans was characterized by mating type, allozyme at the glucose-6-phosphate isomerase (Gpi) and peptidase (Pep) loci, restriction fragment length polymorphism (RFLP) with probe RG57 (provided by W. E. Fry, Cornell University), metalaxyl sensitivity, and aggressiveness on potato and tomato. The number of isolates characterized for mating type, Gpi, and RFLP are presented in Table 1. The characterization procedures are described in Jaime-Garcia et al. (18). Disease severity was recorded according to the late blight disease severity key developed by James (19). Severity estimates correspond roughly to the percentage of foliage that is blighted. Fields where late blight was not found were recorded as zero in disease severity. A network of farmers and technical support personnel surveyed fields informally for the first occurrence of late blight. When late blight was first detected, formal surveys and sample collections began. Fields adjacent to the first outbreak were surveyed first, and later, the entire area was covered.

Geostatistics analysis. A standard geostatistical analysis includes exploratory data analysis, variogram analysis of the spatial structure, surface interpolation, and display of the results (30). In geostatistics, indicator variables can be used to analyze categorical data (20). Indicator variables have only two values, 0 or 1 , and can be analyzed for spatial structure just as continuous variables are analyzed. In our case, particular genotypes or mating types are transformed to indicator variables by scoring them as 1 or 0 , depending on whether the trait is present or absent. Ordinary kriging of indicator variables provides a surface map of the probability of occurrence of the genotype or mating type $(17,20)$.

Variogram analyses. Variograms provide a way to describe the spatial autocorrelation. The lower the variogram value, the higher the correlation. In geostatistics, variogram values derived from the data (experimental variograms) are fit with model variogram functions using three parameters called the range, nugget, and sill. The range is the distance over which the spatial autocorrelation occurs. The nugget and sill estimate the magnitude of the variability that occurs: the nugget estimating very short-range variability and measurement error and the sill estimating the additional total variability over the range. By selecting a model variogram function and values for the parameters, a mathematical description of the spatial autocorrelation is determined in a way that can be used for surface interpolation (kriging). Software for variogram analysis allows for the characterization of directional effects. "Anisotropy" refers to spatial autocorrelation that varies with direction.

Omnidirectional and directional experimental variograms were obtained using the VARIOWIN 2.1 software (Y. Pannatier, 1994; Institute of Mineralogy and Petrography, University of Lausanne, Switzerland) for mating type, allozyme genotypes (Gpi and Pep), RFLP genotypes of $P$. infestans, and late blight severity each season. Specific data of variogram construction and modeling, as well as of reliability, are presented in Table 2. Data from tomato and potato fields were combined for variogram analysis to maximize the number of locations used each season. Fitting of model variograms also was accomplished with the Variowin software. The model variograms were used in ordinary block kriging for estimation in unsampled areas. Variogram equations and procedures to develop experimental variograms and to fit model variograms are presented elsewhere $(5,8,17,20,26)$.

Block kriging. The block kriging procedure was used to estimate average values in unsampled areas. This can be thought of as interpolation of a variable across a surface. Block kriging used the point data of $P$. infestans genotypes and disease severity and incorporate the inherent spatial continuity given by the variogram model to estimate values in blocks or grids of $5 \times 5 \mathrm{~km}$. It was accomplished with either SURFER (Golden Software Inc., Golden, Colorado) or GEOEAS (U.S. Environmental Protection Agency, EMSL-LV, EAD, Las Vegas). The interpolation of unsampled areas by block kriging was done with a search neighborhood of $25,000 \mathrm{~m}$, and 8 to 12 sample locations were included in the kriging process. For the variables Gpi, Pep, mating type, and RFLP genotypes, indicator kriging was performed with results from all isolates found on both potato and tomato throughout the whole season. Ordinary block kriging was used to develop regional maps of disease severity based on data from all tomato and potato fields surveyed. The data were analyzed for the crops separately and together. The disease severity data in the seasons of 1995-96 and 1996-97 were also classified as early severity (the diseased fields found prior to 1 February) and late severity (the diseased fields found throughout the entire season).

Mapping and data display. Base maps of the Del Fuerte Valley, previously digitized for other studies (28), included features such as roads, canals, cities, rivers, and coastline georeferenced in the UTM coordinate system. ARCVIEW version

TABLE 1. Number of isolates of Phytophthora infestans from tomato and potato characterized for mating type, glucose-6-phosphate isomerase (Gpi), restriction fragment length polymorphism (RFLP) patterns, and late blight severity on tomato and potato during the seasons 1994-95, 1995-96, and 1996-97 in the Del Fuerte Valley, Sinaloa, Mexico

\begin{tabular}{|c|c|c|c|c|c|c|c|c|c|}
\hline \multirow[b]{3}{*}{ Year } & & & & \multicolumn{6}{|c|}{ Severity } \\
\hline & \multicolumn{3}{|c|}{ Number of isolates for } & \multicolumn{3}{|c|}{ Tomato } & \multicolumn{3}{|c|}{ Potato } \\
\hline & Mating type & Gpi & RFLP & Fields & Mean & Range & Fields & Mean & Range \\
\hline 1994-95 & 128 & 128 & - & 190 & 9.2 & $0-80$ & 32 & 3.1 & $0-25$ \\
\hline $1995-96$ & 70 & 181 & 17 & 136 & 11.8 & $0-80$ & 43 & 8.7 & 0-99 \\
\hline 1996-97 & 159 & 159 & 83 & 130 & 6.75 & $0-80$ & 109 & 4.2 & $0-90$ \\
\hline
\end{tabular}


3.0a for PCs (ESRI, Redlands, CA) was used to create views and layouts of the kriged values with previously digitized features as background.

\section{RESULTS}

Variogram analysis. All variables, except for mating type in 1996-97 and Pep in 1994-95 and 1996-97, were spatially autocorrelated with model variograms that were best fit using a spherical function (Table 2). The three exceptions did not exhibit spatial variation because they had only one value for all the points sampled. The ranges of the model variograms were between 5,300 and $27,000 \mathrm{~m}$. The shortest range occurred in 1995-96 for disease severity, in 1994-95 for mating type, and in 1996-97 for Gpi. In general, variability was highest during the 1995-96 season, indicated by the nugget plus the sill (Table 2). Anisotropy was observed only for disease severity and, although it was observed in all three seasons, the directional effect varied each season with a different ratio, distance, and direction (Table 2). The other variables did not show anisotropy in the three seasons studied.

Genotype probability maps. The probability maps of mating types of $P$. infestans derived from indicator kriging illustrate the shift from A2 dominating in 1994-95 to A1 dominating in 199697 (Fig. 1). Figure 1 shows areas with the highest probability of finding both mating types occurring together, which is one of the requisites for sexual reproduction of $P$. infestans. In the seasons of 1994-95 and 1995-96, there were areas in the central part of the valley where the probability of finding mating-types A1 and A2 are each in the range of 0.35 to 0.65 . In 1994-95, there was a relatively small area $(10 \times 10 \mathrm{~km})($ Fig. 1B) and in 1995-96, there were two areas in the central part of the valley where the probability of occurrence of each mating type was between 0.35 and 0.65 (Fig. 1C and D). In 1994-95, the mating type with the highest probability of being found throughout the region was the A2 (Fig. 1B). However, in the 1996-97 season, the probability of occurrence of mating-type A2 was estimated to be zero because no A2 isolates were found (Fig. 1F).

Four Gpi loci were present in the Del Fuerte Valley during the period of study and none of the four loci alone was consistently high in probability of occurrence (Fig. 2). In the 1994-95 season, the most likely Gpi locus to be isolated was Gpi 100/111 (Fig.
2B), whereas Gpi 100/122 was most likely in most locations in 1995-96 (Fig. 2G) and 1996-97 (Fig. 2I). The most variability in the Gpi genotype occurred in the 1995-96 season. The Gpi 100/122 locus was widespread (Fig. 2G), but the locus Gpi $111 / 122$ had the highest probability of occurrence in the northwestern and south-central parts of the valley (Fig. $2 \mathrm{H}$ ) and the locus Gpi 100/111 was high in small areas in the central part of the valley (Fig. 2F). In the 1996-97 season, only Gpi loci 100/100 and 100/122 were found (Fig. 2I and K). Gpi 100/100 was most probable $(>0.5)$ in a limited area in the northern and southeastern part of the valley away from the coast (Fig. 2I). In the south and western area, close to the sea, the probability of occurrence of $G p i$ $100 / 100$ was very low (0 to 0.1$)$.

Only two Pep loci were present in the Del Fuerte Valley during the period of study. Pep 100/100 was the only Pep locus found in the 1994-95 season and had the highest probability of occurrence in most areas in the other seasons. Pep 92/100 had the highest probability of occurrence in the western part of the valley in the 1995-96 season and was present with a low probability of occurrence in the northeast part of the valley in 1996-97.

$P$. infestans genotypes characterized by RFLP patterns were analyzed in the 1995-96 and 1996-97 seasons. Probability estimates for the 1995-96 season were based on a small number of data points (only 17), but six different RFLP genotypes were represented. The spatial patterns for the three most common genotypes in 1995-96 show that each genotype is centered in a different location (Fig. 3A, C, and E). There are two small areas, each $10 \times 5 \mathrm{~km}$, where the three genotypes had a similar probability ( 0.35 to 0.5$)$ of occurrence. These areas are just north of the Del Fuerte River and in the central part of the valley at the southeastern part of the estimated area (Fig. 3A, C, and E). In 1996-97, three RFLP banding pattern genotypes were found. The genotype "B" had the highest probability of occurrence in most areas (Fig. 3B), except to the northeast and southeast where the genotype " $\mathrm{H}$ " was more probable (Fig. 3D). The genotype "I" had a low probability of occurrence, with the probability above 0.1 only in a small area $20 \mathrm{~km}$ northeast of Los Mochis (Fig. 3F).

Disease severity. Estimated late blight severity maps of the Del Fuerte Valley show, in general, higher severity in the northwest half of the valley (Fig. 4B to E), except for the 1996-97 season when the south part of the valley had high estimated severity late

TABLE 2. Variogram models for late blight severity, and glucose-6-phosphate isomerase (Gpi), peptidase (Pep), restriction fragment length polymorphism (RFLP) patterns, and mating type of Phytophthora infestans isolates during the seasons 1994-95, 1995-96, and 1996-97 in the Del Fuerte Valley, Sinaloa, Mexico

\begin{tabular}{|c|c|c|c|c|c|c|c|c|c|c|}
\hline \multirow[b]{3}{*}{ Variable } & \multirow[b]{3}{*}{ Type } & \multirow[b]{3}{*}{ Nugget } & \multicolumn{4}{|c|}{ Variogram model } & \multirow{3}{*}{$\begin{array}{c}\text { Goodness } \\
\text { of fit }\end{array}$} & \multicolumn{3}{|c|}{ Anisotropy (range) } \\
\hline & & & \multirow[b]{2}{*}{ Sill $^{\mathrm{a}}$} & \multirow[b]{2}{*}{ Range (m) } & \multicolumn{2}{|c|}{ Lag distance (m) } & & \multirow{2}{*}{$\begin{array}{c}\text { Short } \\
(\text { direction })^{\mathrm{b}}\end{array}$} & \multirow{2}{*}{$\begin{array}{c}\text { Long } \\
{(\text { direction })^{\mathrm{b}}}^{\text {dire }}\end{array}$} & \multirow[b]{2}{*}{ Ratio } \\
\hline & & & & & Interval & Maximum & & & & \\
\hline \multicolumn{11}{|l|}{ 1994-95 } \\
\hline Severity & Spherical & 105.00 & 90 & 26,650 & 5,800 & 58,000 & 0.061107 & $15,000(45)$ & $45,000(135)$ & 3.0 \\
\hline Mating type & Spherical & 0.01 & 0.05 & 8,000 & 3,550 & 39,050 & 0.46744 & $\ldots$ & $\ldots$ & $\ldots$ \\
\hline$G p i$ & Spherical & 0.011 & 0.014 & 13,000 & 2,575 & 18,025 & 0.77672 & $\ldots$ & $\cdots$ & $\cdots$ \\
\hline \multicolumn{11}{|l|}{ 1995-96 } \\
\hline Severity & Spherical & 100.00 & 218 & 5,300 & 1,600 & 16,000 & 0.058908 & $2,500(157.5)$ & $15,000(67.5)$ & 6.0 \\
\hline Mating type & Spherical & 0.06 & 0.072 & 13,500 & 3,600 & 28,800 & 0.25196 & $\ldots$ & $\ldots$ & $\ldots$ \\
\hline$G p i$ & Spherical & 0.08 & 0.125 & 16,000 & 5,200 & 52,000 & 0.099033 & $\ldots$ & $\ldots$ & $\ldots$ \\
\hline Pep & Spherical & 0.03 & 0.15 & 23,700 & 5,200 & 52,000 & 0.56684 & $\ldots$ & $\ldots$ & $\ldots$ \\
\hline RFLP-B & Spherical & 0.08 & 0.16 & 15,000 & 8,500 & 42,500 & 1.4733 & $\ldots$ & $\ldots$ & $\ldots$ \\
\hline RFLP-C & Spherical & 0.00 & 0.15 & 15,000 & 8,500 & 42,500 & 1.7846 & $\ldots$ & $\ldots$ & $\ldots$ \\
\hline RFLP-D & Spherical & 0.06 & 0.12 & 20,000 & 5,500 & 27,500 & 0.76025 & $\ldots$ & $\ldots$ & $\ldots$ \\
\hline \multicolumn{11}{|l|}{ 1996-97 } \\
\hline Severity & Spherical & 85.00 & 135 & 18,000 & 4,250 & 51,000 & 0.056677 & $7,000(90)$ & $28,000(0)$ & 4.0 \\
\hline$G p i$ & Spherical & 0.065 & 0.094 & 7,000 & 4,800 & 48,000 & 0.050310 & $\ldots$ & $\ldots$ & $\ldots$ \\
\hline RFLP-B & Spherical & 0.1 & 0.072 & 10,000 & 4,500 & 36,000 & 0.029595 & $\ldots$ & $\ldots$ & $\ldots$ \\
\hline RFLP-H & Spherical & 0.1 & 0.072 & 10,000 & 4,500 & 36,000 & 0.029595 & $\ldots$ & $\ldots$ & $\ldots$ \\
\hline RFLP-I & Spherical & 0.1 & 0.072 & 10,000 & 4,500 & 36,000 & 0.029595 & $\ldots$ & $\ldots$ & $\ldots$ \\
\hline
\end{tabular}

a This value represent the sill (call the scale in some literature) of the variogram, which is the total sill minus the nugget.

${ }^{\mathrm{b}}$ Direction in degrees from north. 
in the season (Fig. 4F). Severity estimated with fields that were infected with late blight before 1 February in 1995-96 and 199697 showed that late blight was likely to be found early only in the areas of the northern or northwestern half of the valley. Later, higher severity $(>5 \%)$ of late blight was found throughout the valley including the southeast half, although it still was lower ( 5 to $15 \%$ ) in the southeast than the northwest (>15\%) (Fig. 4B and D). In the 1996-97 season, the areas of high disease severity shifted from the north to the south. There was a high disease severity $(>5 \%)$ early in the season in the north and a high disease severity $(>5 \%)$ later in the season in the south, leaving the central part with a very low estimated disease severity $(<2 \%)$ (Fig. $4 \mathrm{E}$ and $F$ ).

The estimated late blight severity in tomato and potato separately showed that disease severity was higher in tomato (Fig. 5). The spatial patterns of disease severity in tomatoes were quite
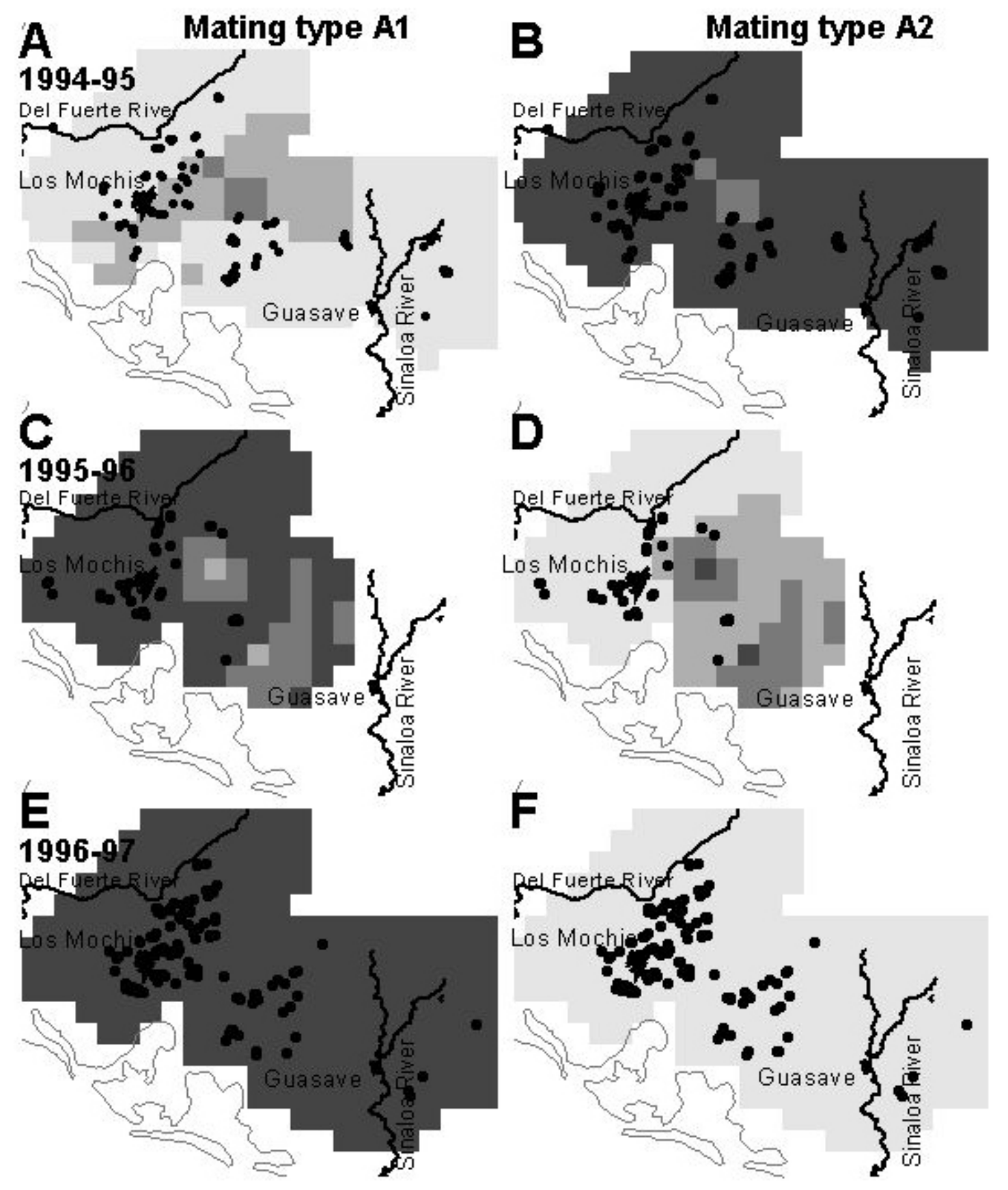

Probability of occurrence
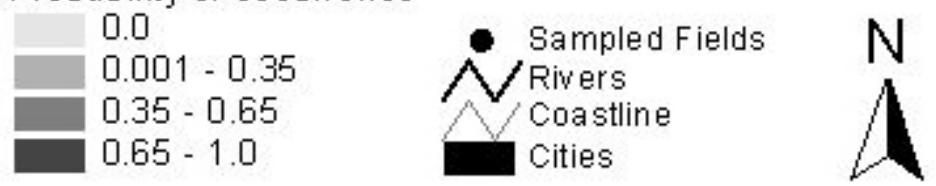

$\begin{array}{lllll}10 & 0 & 10 & 20 & \text { Kilometers }\end{array}$

Fig. 1. Probability of occurrence of Phytophthora infestans mating types of A, C, and E, A1 and $\mathbf{B}, \mathbf{D}$, and F, A2 in the Del Fuerte Valley, Sinaloa, Mexico, during the seasons of $\mathbf{A}$ and B, 1994-95, $\mathbf{C}$ and D, 1995-96, and $\mathbf{E}$ and F, 1996-97 based on indicator kriging (5 $\times 5 \mathrm{~km}$ blocks) of the presence or absence of each mating type in sample fields. A search neighborhood of $25,000 \mathrm{~m}$ and 8 to 12 point samples were used to generate the kriging estimates. Dots represent the sampled fields from which the probability maps were generated. 
similar to that estimated for the two crops together in the three seasons. The estimated severity in potatoes in the 1994-95 season was lower than $5 \%$ in most of the region, except for small areas near to the coast where severity was between 5 and $15 \%$. This area, southwest of Los Mochis, was higher in estimated severity all three seasons (Fig. 5A, C, and D). Analyzed separately, severity in potatoes was consistently higher near the coast (Fig. 5A, C, and E) and severity in tomatoes was consistently high in two areas, near the coast and in the northern part of the study area near the Del Fuerte River (Fig. 5B, D, and F).

\section{DISCUSSION}

The analysis of the spatial structure of both the late blight data and of its pathogen $P$. infestans data indicates spatial autocorrelation of the variables used to characterize the late blight epidemics in the Del Fuerte Valley, Sinaloa, Mexico. The variograms of all the variables in the study present the same type of variogram model, the spherical. Most genotype variables showed spatial autocorrelation in a range of 13,000 to $20,000 \mathrm{~m}$ in a valley that is 150,000 by $70,000 \mathrm{~m}$. This suggests localized sources and restricted spread of some genotypes. Some genotypes are patchy in their distribution and the probability maps generated by kriging helped visualize those patches. The patchiness of genotypes has implications for management of late blight because $P$. infestans genotypes differ in some features that are important for management such as metalaxyl sensitivity and aggressiveness to tomato and potato (24).

The geostatistical analysis allowed us to look for underlying directionality that would not be obvious from the display of points alone. No anisotropy was found in the data on the pathogen $P$. infestans (mating type, allozymes, and RFLP genotypes), but anisotropy was observed in late blight severity each season, although the direction and the extent of this anisotropy differed each year. This suggests that the severity of late blight epidemics in the Del Fuerte Valley have different spatial structure each year. This spatial structure can be affected by several factors that may change from season to season including weather, prevalent winds, host, and genotype patterns. The spatial continuity allows us to use the models obtained by the variograms in the estimation of data of these variables in unsampled areas by using the estimator method called kriging.

Indicator kriging is a tool used to interpolate the results of genotype analyses across the region and visualize major shifts in the genetic structure through use of probability maps. The probability of occurrence of $P$. infestans allozyme genotypes indicates that each year in the Del Fuerte Valley the epidemics of late blight

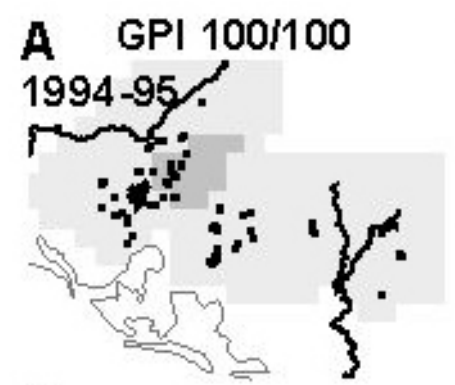

E

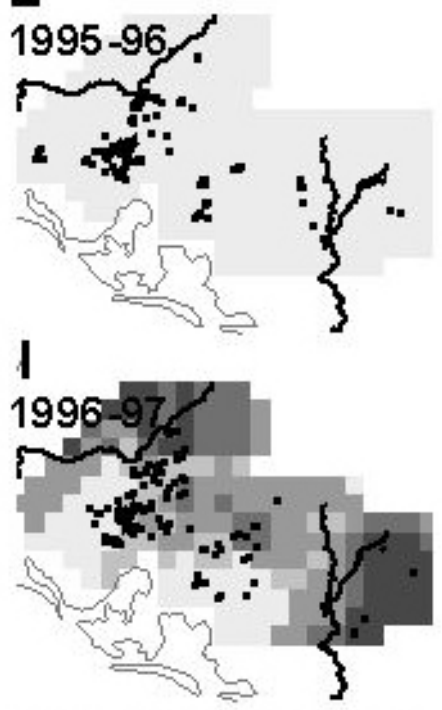

$\mathbf{F}$
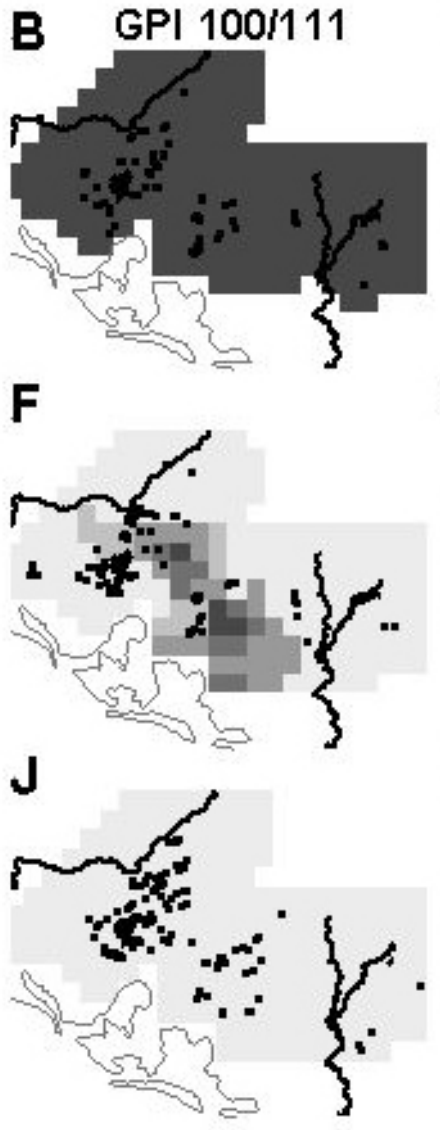

Probability of occurrence

0

$0.001-0.15$

$0.15-0.35$

$0.35-0.5$

$0.5-1$

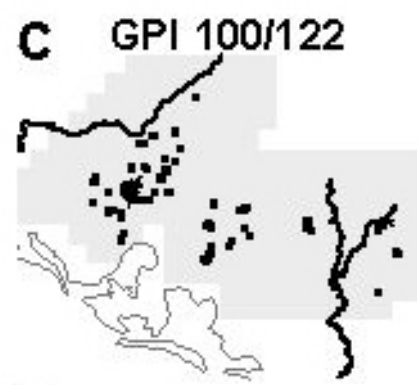

G
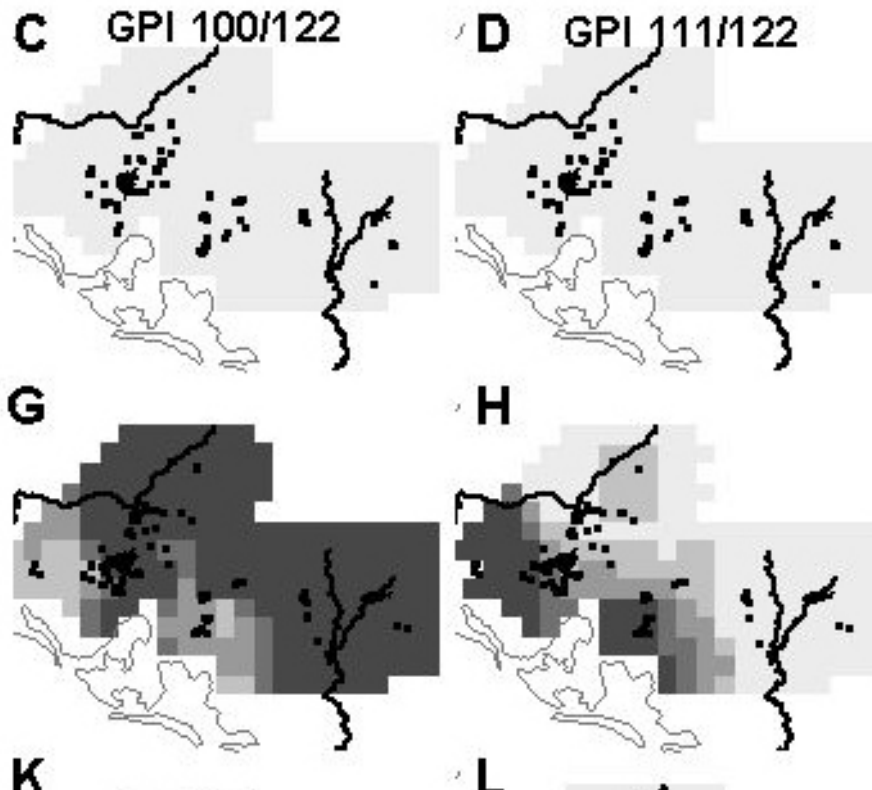

H
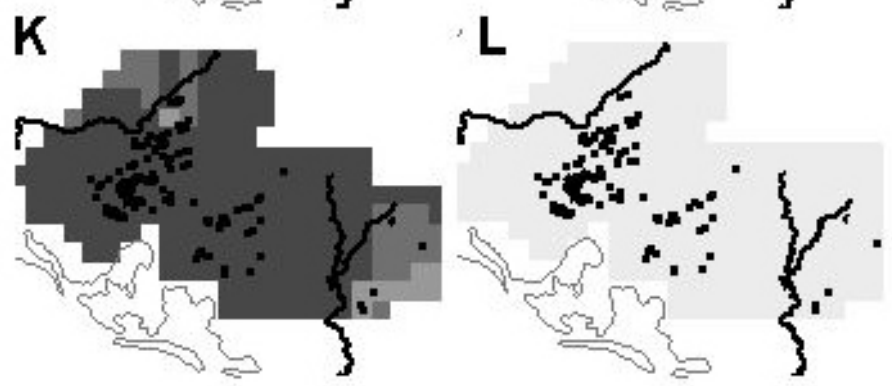

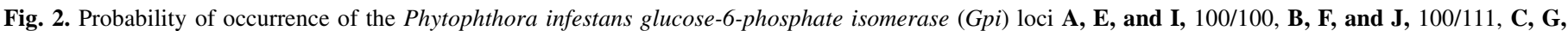

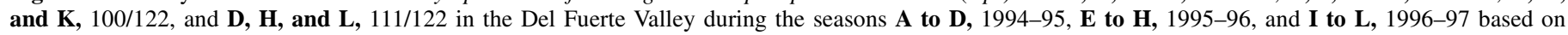

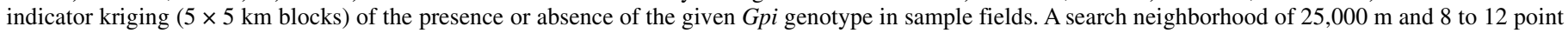
samples were used to generate the kriging estimates. Dots represent the sampled fields from which the probability maps were generated. 
are largely dominated by only one genotype (Fig. 2). This indicates a strong clonal population of this pathogen in this area. The shift of Gpi genotypes from year to year supports the idea that the pathogen is introduced to the area each year (18). However, in addition to the dominant allozyme genotype, other genotypes were present each year in low frequencies or in restricted areas. This was explored further with analysis of RFLP genotypes.

The probability maps of RFLP genotypes in the 1995-96 and 1996-97 seasons in the Del Fuerte Valley suggest geographic genetic substructuring (10) of $P$. infestans. Geographic substructuring was more evident in the 1995-96 season, where three different RFLP patterns were present in the northwestern part of the valley. Pattern "B" is most probable around Los Mochis (Fig. 3A), pattern " $\mathrm{C}$ " is most probable southwest of Los Mochis (Fig. 3C), and pattern " $\mathrm{D}$ " is most probable in the north (Fig. 3E). The probability maps also suggest that the three genotypes are likely to cooccur toward the southeast part of the valley, which is generally downwind of the northwestern sites. Although the RFLP patterns
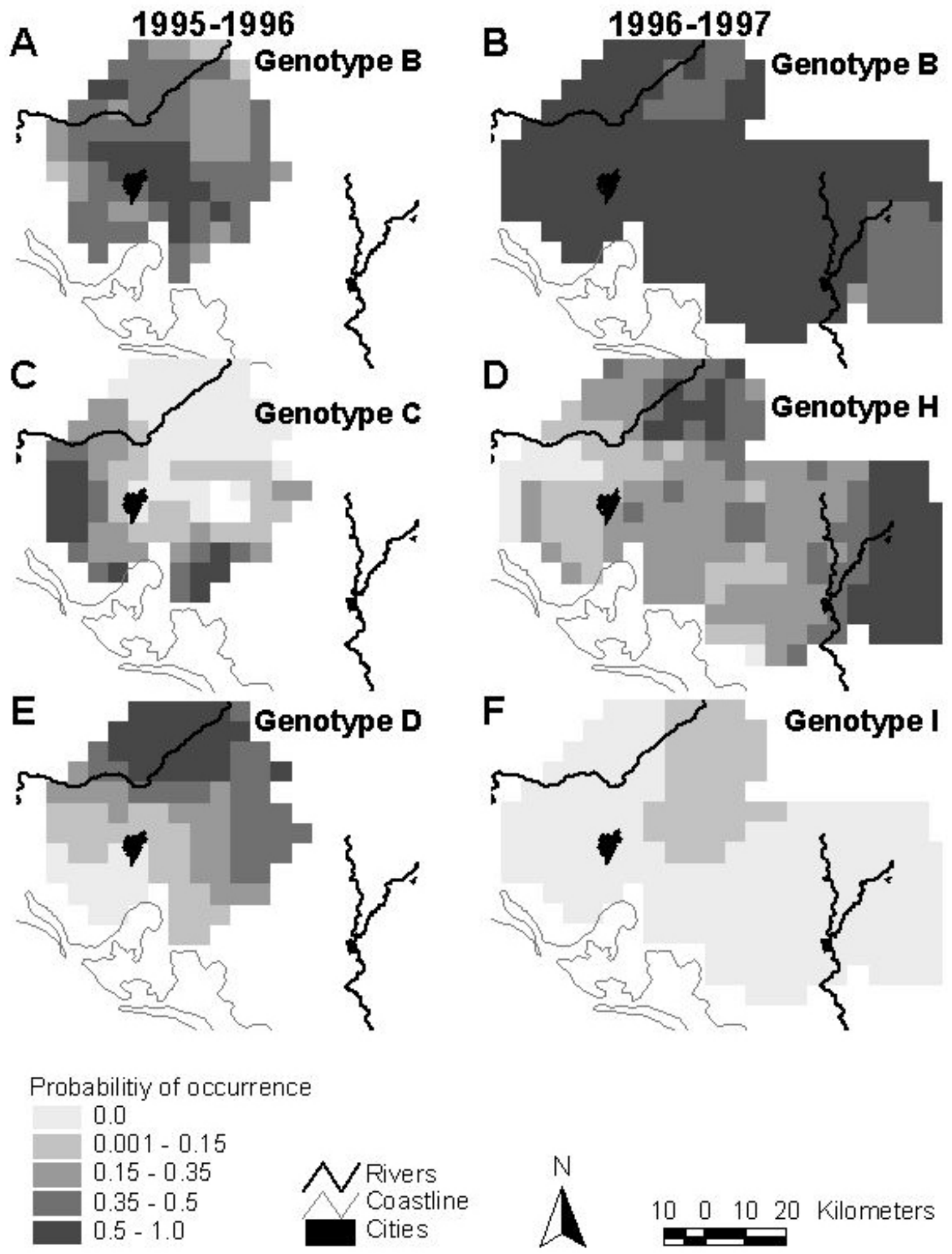

Fig. 3. Probability of occurrence of Phytophthora infestans restriction fragment length polymorphism (RFLP) genotypes banding pattern A and B, "B"; C, "C"; D, "H"; E, "D"; and F, "I" in the Del Fuerte Valley during the seasons A, C, and E, 1995-96 and B, D, and F, $1996-97$ based on indicator kriging (5 × 5 km blocks) of the presence or absence of the given RFLP pattern genotype in sample fields. A search neighborhood of $25,000 \mathrm{~m}$ and 8 to 12 point samples were used to generate the kriging estimates. 
in this season should be viewed with caution because they are based on a small number of points (17 points), they are included here because they illustrate the possibility of genotypes converging downwind of areas of origin and because they illustrate, more generally, how genotype probability maps can be applied to the study of genetic structure. RFLP pattern "B", which had a high probability of occurrence in 1995-96, was dominant in the 199697 season (Fig. 3B), and was the only RFLP genotype occurring on both tomato and potato in 1995-96 (18). RFLP genotype "H" was restricted in location (Fig. 3D), was found only on tomato, and was not aggressive on potato in laboratory tests (18). The low aggressiveness on potato could be a factor that restricts this genotype spatially. This analysis suggests that potatoes may have an important role in the epidemic cycles in this area.

Probability maps are also useful in the analysis of the likelihood of sexual reproduction. Both mating types of $P$. infestans must be present for sexual reproduction. Sexual reproduction is the most important source of genetic variation of this organism $(10,13)$, and
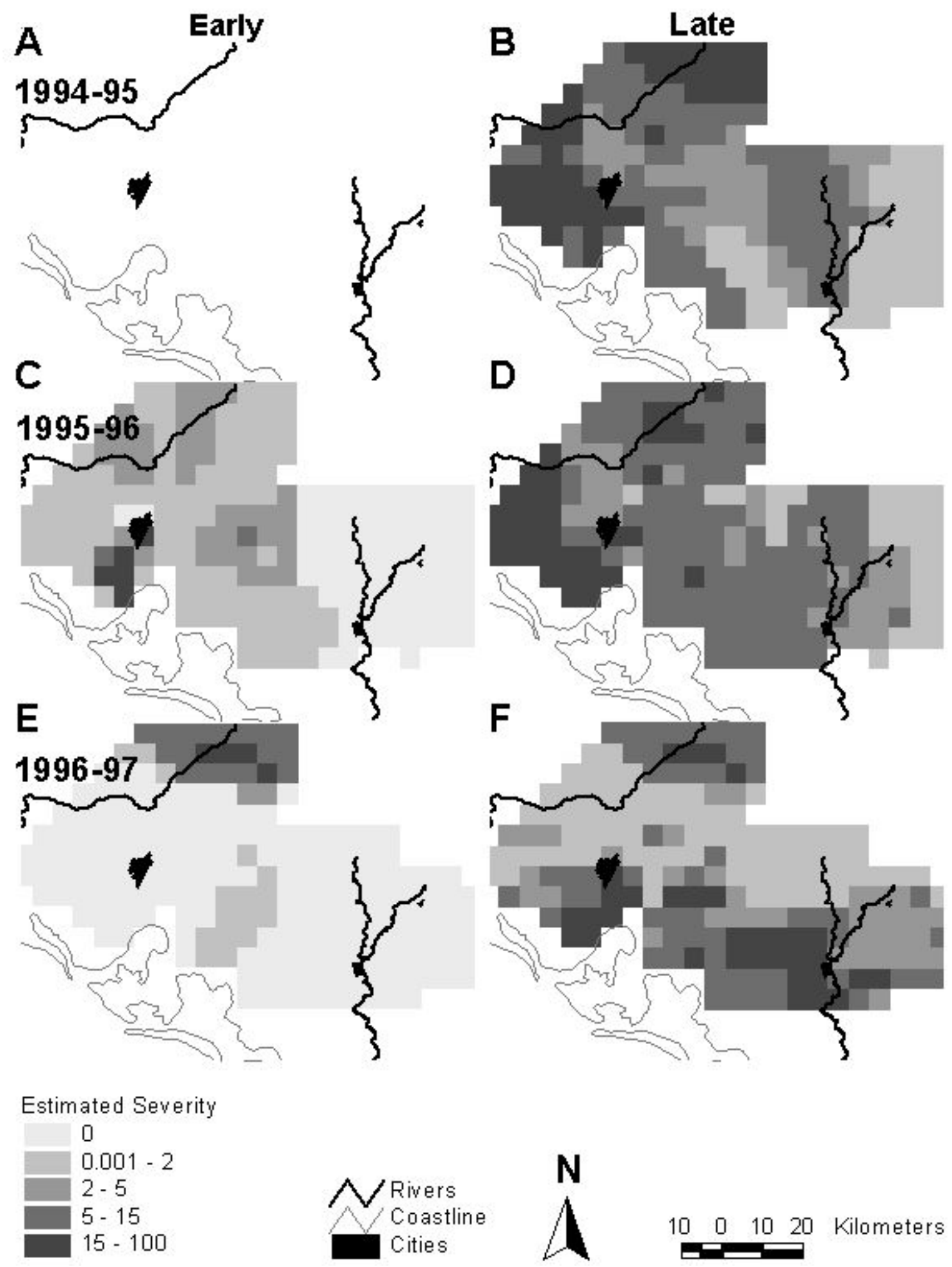

Fig. 4. Estimated late blight severity on tomato and potato $\mathbf{A}, \mathbf{C}$, and $\mathbf{E}$, early and $\mathbf{B}, \mathbf{D}$, and $\mathbf{F}$, late in the season in the Del Fuerte Valley during the seasons A and B, 1994-95, C and D, 1995-96, and E and F, 1996-97 based on block kriging (5 $\times 5 \mathrm{~km}$ blocks) of the severity data from both the tomato and potato fields surveyed. A search neighborhood of $25,000 \mathrm{~m}$ and 8 to 12 point samples were used to generate the kriging estimates. 
the resulting oospores are a potential survival structure during the off-season. $P$. infestans is unlikely to persist vegetatively in an area where the weather conditions are unfavorable during the resting time because either it prevents infections of late blight or no susceptible hosts are growing. In the case of the Del Fuerte Valley, only in small areas in the central part of the valley did both mating types have similar probabilities of occurrence in the 1994-95 and 1995-96 seasons (Fig. 1). Even though the presence of both mating types suggests possibility of sexual reproduction, we have to consider the optimum weather for sexual reproduction to occur (4). Although, in the Del Fuerte Valley, the optimal weather conditions for sexual reproduction occasionally may occur, in general, the valley does not have sufficient periods of optimal weather to support a sexually reproducing population. When sexual reproduction is occurring, both mating types are required and both are produced the following year. A1 and A2 mating types were present in both 1994-95 and 1995-96 seasons (Fig. 1). If sexual reproduction occurred in these two seasons, it had no long-

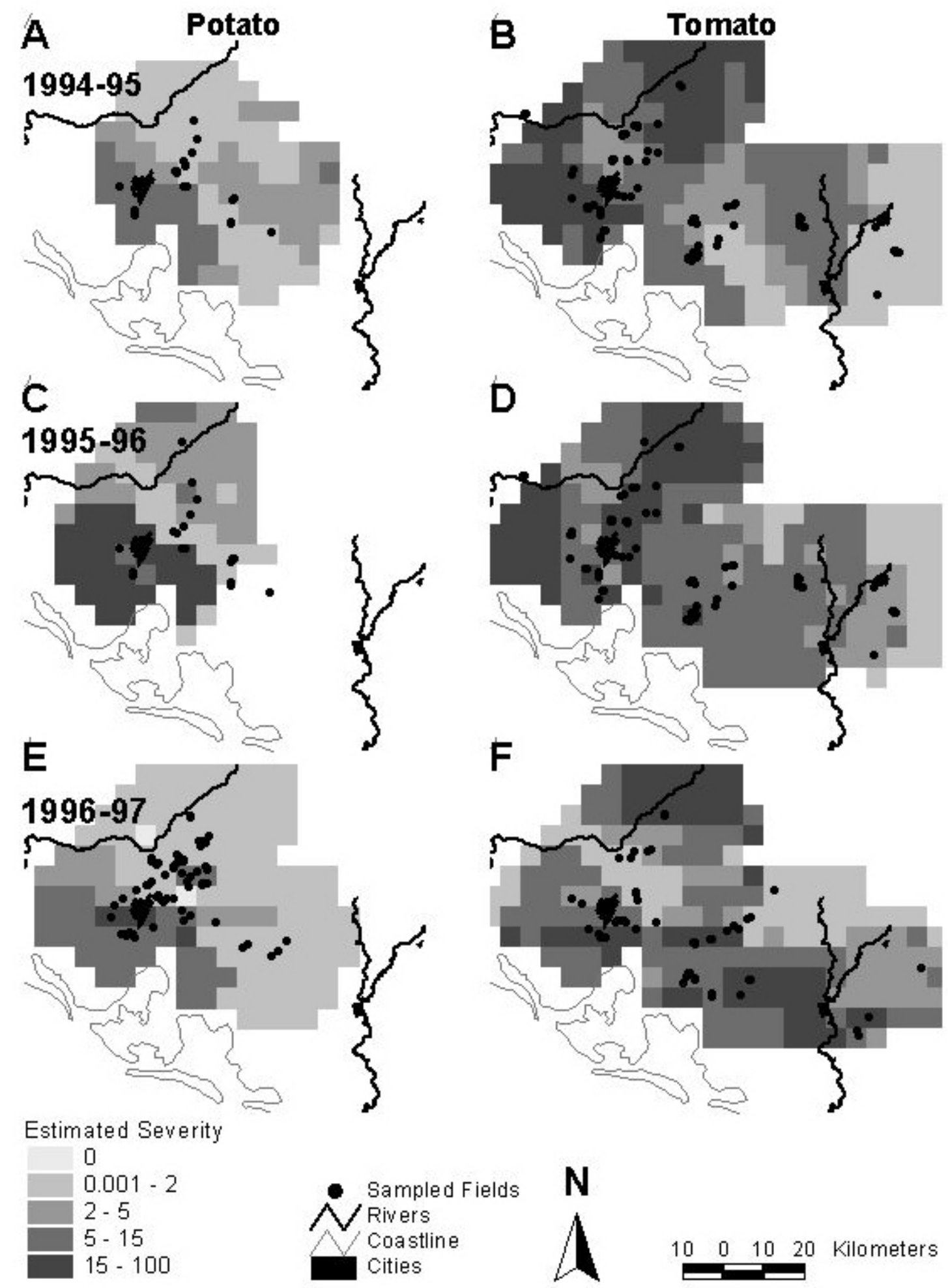

Fig. 5. Estimated late blight severity in A, C, and E, potatoes and B, D, and F, tomatoes in the Del Fuerte Valley during the seasons A and B, 1994-95, C and $\mathbf{D}, 1995-96$, and $\mathbf{E}$ and $\mathbf{F}, 1996-97$ based on block kriging $(5 \times 5 \mathrm{~km}$ blocks) of the severity data from all the fields surveyed. A search neighborhood of $25,000 \mathrm{~m}$ and 8 to 12 point samples were used to generate the kriging estimates. 
term epidemiological consequence, because in the 1996-97 season, the A2 mating type was not detected despite extensive sampling (Fig. 1F) (18).

It is important to consider the spatial patterns of the $P$. infestans genotypes in terms of management of the disease. In the 1995-96 and 1996-97 seasons, metalaxyl-sensitive genotypes were detected. Metalaxyl is the most effective fungicide for the control of sensitive genotypes of $P$. infestans (24). The Gpi 111/122 in the 1995-96 season was highly sensitive to metalaxyl and had a high probability of occurrence in a restricted area to the south and western part of the city of Los Mochis (Fig. 2H). The Gpi 100/100 in 1996-97 also was highly sensitive to metalaxyl and was restricted mainly to the north and the southeast (Fig. 2I). Furthermore, both genotypes had a low aggressiveness to the most common potato variety planted in the area (18). Considering the characteristics of these genotypes, in those areas where they were most likely to occur, tomato producers could have effectively used the fungicide metalaxyl to control late blight. Furthermore, the potato producers in those areas could have reduced efforts to control late blight, because the genotypes were not aggressive on potato. However, in most areas of the valley in the three seasons, genotypes were highly resistant to metalaxyl and aggressive to both the tomato and potato crops. This indicates that, unless local genotype evidence is to the contrary, efforts to control late blight must be taken on both the tomato and potato crops in most of the area and the fungicide metalaxyl must be avoided in areas with resistant genotypes.

Maps of late blight severity, estimated by kriging, show that severity was higher in tomatoes than in potatoes in the three seasons of study (Fig. 5). The higher severity in tomatoes could be explained by the fact that the genotypes of $P$. infestans occurring in the area were uniformly highly aggressive to tomato and medium to low aggressive to potato (18). Tomato has a bigger and more closed canopy, which provides a more favorable environment for development of late blight. Furthermore, closed canopies also are more difficult to penetrate with fungicide sprays.

The estimated severity on both tomatoes and potatoes was highest in the area southwest of Los Mochis in all three seasons. The most likely causes for the observed pattern is that high severity area is closer to the sea and thus more humid. Also, some farmers in this area gave late blight management a low priority, allowing inoculum to build up locally and spread to other fields.

More generally, estimated severity in tomatoes was high in most of the northwestern half of the valley and low in the southeastern half, particularly in the 1994-95 and 1995-96 seasons (Fig. 5). The northwestern half of the valley is also where genotype patterns are patchy and mating types have co-occurred. In addition, late blight started in this same area each season and spread to the southeastern half of the valley later in the season (after 1 February) (Fig. 4). In the northwestern half of the valley, both tomato and potato crops are grown together, whereas in the southeastern half, only tomatoes are grown. We suspect that the common factor behind these patterns is the introduction of inoculum to the potato crop on potato seed pieces each year and subsequent movement from the potato crop to the more susceptible processing tomato crop. Potato seed pieces are a known source of primary inoculum of $P$. infestans $(1,36)$ and are introduced to this part of the valley each year from areas in Mexico where late blight is common and sexual reproduction occurs $(15,18,32)$.

In some areas, the estimated severity could be overestimated locally due to the presence of one or two fields with very high severity, because both the variogram estimator and the kriging estimator are sensitive to outliers (26). However, this outlier effect can be desirable for some situations dealing with management of late blight. For example, if timely estimated severity maps are intended for risk assessment of the disease during a growing season, then those fields with high severity should be a focus of attention because of the inoculum build-up and, thus, the neigh- borhood around them will be properly identified as a higher risk of infection (34) in the kriging process. In addition, the overestimation due to outliers could be desirable when recurrent patterns are present (28), because if outliers are recurrent spatially then we will be able to detect areas where good management practices are not being taken or where special conditions conducive to late blight are occurring.

In this paper, geostatistics and GIS have been used to analyze the spatial patterns of $P$. infestans genotypes and their relationship with late blight severity in a mixed tomato and potato production area. The analysis of late blight severity has shown some important recurrent patterns such as the early onset of the disease occurring in the area where both potato and tomato are growing, strengthening the hypothesis that infected potato tubers are the main source of primary inoculum. We have found that some genotypes that differ in important ecological features such as metalaxyl sensitivity and aggressiveness to tomato and potato have restricted spread and are localized in separated areas. Maps displaying the probabilities of occurrence of mating types and genotypes of $P$. infestans and disease severity illustrate the desirability of integrating outcomes of genetic analysis of $P$. infestans isolates with GIS and geostatistics, thus, creating the basis for disease management decisions.

\section{ACKNOWLEDGMENTS}

We thank Campbell Research and Development, Concentradora de Tomate S.A. de C.V. (Tomasi), Alimentos Del Fuerte S.A. de C.V., and INIFAP for their cooperation in this project; R. Gamboa, S. Alarcon, M. Encinas, U. Valenzuela, J. G. Gonzalez, and J. Vallejo for their help in collecting samples in the Del Fuerte Valley; and D. E. Myers of the Department of Mathematics at the University of Arizona (retired) for his advice on geostatistical analyses.

\section{LITERATURE CITED}

1. Andrivon, D. 1995. Biology, ecology, and epidemiology of the potato late blight pathogen Phytophthora infestans in soil. Phytopathology 85:1053-1056.

2. Byrne, D. N., Rathman, R. J., Orum, T. V., and Palumbo, J. C. 1996. Localized migration and dispersal by the sweet potato whitefly, Bemisia tabaci. Oecologia 105:320-328.

3. Chellemi, D. O., Rohrbach, K. J., Yost, R. S., and Sonoda, R. M. 1988. Analysis of the spatial pattern of plant pathogens and diseased plants using geostatistics. Phytopathology 78:221-226.

4. Cohen, Y., Farkash, S., Reshit, Z., and Baider, A. 1997. Oospore production of Phytophthora infestans in potato and tomato leaves. Phytopathology 87:191-196.

5. Cressie, N. 1993. Geostatistics: A tool for environmental modelers. Pages 414-421 in: Environmental Modeling with GIS. M. F. Goodchild, B. O. Parks, and L. T. Steyaert, eds. Oxford University Press, London.

6. Cressie, N., and VerHoef, J. M. 1993. Spatial statistical analysis of environmental and ecological data. Pages 404-413 in: Environmental Modeling with GIS. M. F. Goodchild, B. O. Parks, and L. T. Steyaert, eds. Oxford University Press, London.

7. Dandurand, L. M., Knudsen, G. R., and Schotzko, D. J. 1985. Quantification of Pythium ultimum var. sporangiiferum zoospore encystment patterns using geostatistics. Phytopathology 85:186-190.

8. Deutsch, C. V., and Journel, A. G. 1992. GSLIB Geostatistical Software Library and User's Guide. Oxford University Press, London.

9. Fry, W. E., Goodwin, S. B., Dyer, A. T., Matuszak, J. M., Drenth, A., Tooley, P. W., Sujkowski, L. S., Koh, Y. J., Cohen, B. A., Spielman, L. J., Deahl, K. L., Inglis, D. A., and Sandlan, K. P. 1993. Historical and recent migrations of Phytophthora infestans: Chronology, pathways, and implications. Plant Dis. 77:653-661.

10. Fry, W. E., Goodwin, S. B., Matuszak, J. M., Spielman, L. J., and Drenth, A. 1992. Population genetics and intercontinental migrations of Phytophthora infestans. Annu. Rev. Phytopathol. 30:107-129.

11. Goodchild, M. F. 1993. The state of GIS for environmental problem solving. Pages 8-15 in: Environmental Modeling with GIS. M. F. Goodchild, B. O. Parks, and L. T. Steyaert, eds. Oxford University Press, London.

12. Goodchild, M. F., Parks, B. O., and Steyaert, L. T., eds. 1993. Environmental Modeling with GIS. Oxford University Press, London. 
13. Goodwin, S. B. 1997. The population genetics of Phytophthora. Phytopathology 87:462-473.

14. Goodwin, S. B., Cohen, B. A., and Fry, W. E. 1994. Panglobal distribution of a single lineage of the Irish potato famine fungus. Proc. Natl. Acad. Sci. USA 91:11591-11595.

15. Goodwin, S. B., Spielman, L. J., Matuszak, J. M., Bergeron, S. N., and Fry, W. E. 1992. Clonal diversity and genetic differentiation of Phytophthora infestans populations in northern and central Mexico. Phytopathology 82:955-961.

16. Gottwald, T. R., Avinent, L., Llácer, G., Hermoso de Mendoza, A., and Cambra, M. 1995. Analysis of the spatial spread of sharka (Plumb pox virus) in apricot and peach orchards in eastern Spain. Plant Dis. 79:266-278.

17. Isaaks, E. H., and Srivastava, R. M. 1989. An Introduction to Applied Geostatistics. Oxford University Press, London.

18. Jaime-Garcia, R., Trinidad-Correa, R., Felix-Gastelum, R., Orum, T. V., Wasmann, C. C., and Nelson, M. R. 2000. Temporal and spatial patterns of genetic structure of Phytophthora infestans from tomato and potato in the Del Fuerte Valley. Phytopathology 90:1188-1195.

19. James, C. 1971. A manual of assessment keys for plant diseases. Can. Dep. Agric. Publ. 1458.

20. Journel, A. G. 1989. Fundamentals of Geostatistics in Five Lessons. American Geophysical Union, Washington, D.C.

21. Larkin, R. P., Gumpertz, M. L., and Ristaino, J. B. 1995. Geostatistical analysis of Phytophthora epidemic development in commercial bell pepper fields. Phytopathology 85:191-203.

22. Lecoustre, R., Fargette, D., Fauquet, C., and de Reffye, P. 1989. Analysis and mapping of the spatial spread of African cassava mosaic virus using geostatistics and the kriging technique. Phytopathology 79:913-920.

23. Liebhold, A. M., Rossi, R. E., and Kemp, W. P. 1993. Geostatistics and geographic information systems in applied insect ecology. Annu. Rev. Entomol. 38:303-327.

24. Milgroom, M. G., and Fry, W. E. 1997. Contributions of population genetics to plant disease epidemiology and management. Pages 1-30 in: Advances in Botanical Research, Vol. 24. Incorporating Advances in Plant Pathology. J. H. Andrews and I. C. Tommerup, eds. Academic Press, New York.

25. Monestiez, P., Goulard, M., and Charmet, G. 1994. Geostatistics for spatial genetic structures: Study of wild populations of perennial ryegrass. Theor. Appl. Genet. 88:33-41.

26. Myers, D. E. 1991. Interpolation and estimation with spatially located data. Chemom. Intell. Lab. Syst. 11:209-228.

27. Myers, D. E. 1993. Spatial statistics. Pages 401-403 in: Environmental Modeling with GIS. Section VI. M. F. Goodchild, B. O. Parks, and L. T. Steyaert, eds. Oxford University Press, London.

28. Nelson, M. R., Felix-Gastelum, R., Orum, T. V., Stowell, L. J., and Myers, D. E. 1994. Geographic information systems and geostatistics in the design and validation of regional plant virus management programs. Phytopathology 84:898-905.

29. Nelson, M. R., and Orum, T. V. 1997. Geographic information systems and geostatistics in the design of regional plant disease and insect pest management programs. AAAS Annu. Meet. Sci. Innov. Expo. 163:A22.

30. Nelson, M. R., Orum, T. V., Jaime-Garcia, R., and Nadeem, A. 1999. Applications of geographic information systems and geostatistics in plant disease epidemiology and management. Plant Dis. 83:308-319.

31. Nicholson, M. C., and Mather, T. N. 1996. Methods for evaluating Lyme disease risks using geographic information systems and geospatial analysis. J. Med. Entomol. 33:711-720.

32. Niederhauser, J. S. 1991. Phytophthora infestans: The Mexican connection. Pages 25-45 in: Phytophthora. J. A. Lucas, R. C. Shattock, D. S. Shaw, and L. R. Cooke, eds. British Mycological Society, Cambridge University Press, Cambridge.

33. Orum, T. V., Bigelow, D. M., Nelson, M. R., Howell, D. R., and Cotty, P. J. 1997. Spatial and temporal patterns of Aspergillus flavus strain composition and propagule density in Yuma County, Arizona, soils. Plant Dis. 81:911-916.

34. Real, L. A., and McElhany, P. 1996. Spatial patterns and process in plant-pathogen interactions. Ecology 77:1011-1025.

35. Stein, A., Kocks, C. G., Zadoks, J. C., Frinking, H. D., Ruissen, M. A., and Myers, D. E. 1994. A geostatistical analysis of the spatio-temporal development of the downy mildew epidemics in cabbage. Phytopathology 84:1227-1239.

36. Wastie, R. L. 1991. Breeding for resistance. Pages 193-224 in: Advances in Plant Pathology, Vol. 7. Phytophthora infestans, The Cause of Late Blight of Potato. D. S. Ingram and P. H. Williams, eds. Academic Press, New York.

37. Webster, R., and Boag, B. 1992. Geostatistical analysis of cyst nematodes in soil. J. Soil Sci. 43:583-595.

38. White, J. G., Welch, R. M., and Norvell, W. A. 1997. Soil zinc map of the USA using geostatistics and geographic information systems. Soil Sci. Soc. Am. J. 61:185-194. 